\title{
O CONHECIMENTO HISTÓRICO ENTRE MAPAS E JOGOS: O ENSINO DE GRÉCIA ANTIGA A PARTIR DO JOGO DE TABULEIRO
}

\section{HISTORICAL KNOWLEDGE BETWEEN MAPS AND GAMES: TEACHING OF ANCIENT GREECE FROM A BOARD GAME}

\author{
Carolina Ferreira de Figueiredo* \\ Lucas Werlang Girardi ${ }^{* *}$
}

\begin{abstract}
Resumo: Este trabalho visa refletir sobre a utilização de jogos no ensino de História a partir de uma experiência docente com estudantes do sexto ano do Ensino Fundamental. A elaboração do jogo de tabuleiro, confeccionado pelos/as docentes, teve como finalidade abordar questões relativas ao conteúdo de Grécia Antiga, tanto já trabalhado em sala de aula através de outras metodologias, quanto novas informações a serem refletidas propriamente a partir do jogo. Através desta experiência didática, discutese sobre pressupostos do ensino de História que dialogam com o lúdico em sala de aula, especialmente no que diz respeito ao desenvolvimento da consciência histórica dos/as estudantes, visando propor um ensino-aprendizagem voltado para o uso prático e cotidiano da história, bem como o estabelecimento de conhecimentos interdisciplinares. Também, desenvolve-se uma reflexão sobre o aspecto lúdico e como este possibilita ferramentas de socialização e aprendizagem dentro do ambiente escolar, especialmente a partir da formatação do jogo proposto.
\end{abstract}

Palavras-chave: Ensino de História. Jogos. Lúdico. Grécia Antiga. Consciência histórica.

\begin{abstract}
This work aims to reflect on the use of games in the teaching of history from a classroom experience with sixth grade students on Elementary School. The elaboration of the board game, made by the teachers, aimed to address issues related to the content of Ancient Greece, both worked in the classroom through other methodologies, and new information to be reflected from the game itself. Through this experience, we discuss assumptions of the teaching of history that dialogue with the playful aspect in the classroom, especially with regard to the development of students' Historical Consciousness, aiming to propose a teaching-learning focused on practical and daily use of history as well as the establishment of interdisciplinary knowledge. Also, we develop a reflection on the playful aspect, and how it enables socialization and learning tools within the school environment, especially from the formatting of the proposed game.
\end{abstract}

Keywords: History Teaching. Games. Ludic. Ancient Greece. Historical Consciousness.

\section{Introdução}

Este trabalho tem por objetivo propor uma reflexão acerca das possibilidades do uso de jogos em sala de aula e no ensino de História, a partir de uma experiência realizada com estudantes do sexto ano do Ensino Fundamental de uma escola pública municipal. Mais especificamente, pretende-se discutir sobre as problemáticas de nível teóricometodológico acerca do aspecto lúdico nas aulas de História e de que maneiras estas

\footnotetext{
* Universidade Federal do Rio de Janeiro. Mestra em História pela Universidade Federal do Rio Grande do Sul (UFRGS). Doutoranda em História pelo Programa de Pós-Graduação em História Social da Universidade Federal do Rio de Janeiro (UFRJ) e bolsista da Fundação de Amparo à Pesquisa do Estado do Rio de Janeiro (FAPERJ). E-mail: carolina.ferreirafigueiredo@gmail.com

** Universidade Estadual do Sudoeste da Bahia (UESB).Mestre em História pela Universidade de São Paulo (USP). Doutorando em História pela Universidade Federal Fluminense (UFF) e Professor Substituto de História Antiga e Medieval da Universidade Estadual do Sudoeste da Bahia (UESB).

E-mail: lucaswgirardi@hotmail.com
} 
podem propor relações de aprendizado diferenciadas, na teoria e na prática, a partir do jogo de tabuleiro confeccionado por docentes sobre Grécia Antiga e jogado pelos/as estudantes.

Uma questão recorrente ao ensino de História e à prática docente é a articulação dos conteúdos programáticos a serem desenvolvidos no ano escolar e os conhecimentos e habilidades desenvolvidas a partir desse encontro de saberes. Isso porque se parte do entendimento de que os/as estudantes possuem conhecimentos próprios, ideias prévias (SCHMIDT; URBAN, 2016) anteriores e diferentes do conhecimento escolar, que são ativados, incorporados e modificados junto ao processo de ensino-aprendizagem possibilitado pela escola. Assim, reflete-se sobre como o ensino de uma história que já passou - uma "história acontecimento", gerada no passado - pode construir conhecimento e ser instrumentalizada pelos/as estudantes.

O historiador Peter Lee (2011), no artigo "Por que aprender história?", aborda aspectos formativos da história e, ao informar sobre a ambiguidade desta a partir da obra de John H. Plumb, destaca que a história é também "[...] uma fonte de sabedoria positiva, fornecendo os conhecimentos dos 'mecanismos das mudanças históricas', demonstrando o papel da razão nos sucessos humanos e, portanto, preenchendo, pelo menos, alguns dos significados do passado morto" (LEE, 2011, p. 22). Essas mudanças históricas podem ser mobilizadas e percebidas através da abordagem didática do jogo.

A atividade com o jogo de tabuleiro foi realizada com quatro turmas de sexto ano do Ensino Fundamental da Escola Municipal Monteiro Lobato, hoje chamada de Escola Municipal Rosalina Calegário, no município de Simonésia, em Minas Gerais. A cidade de Simonésia se encontra na região chamada de Zona da Mata Mineira, situada no sudeste do estado de Minas Gerais, tendo, segundo informações da Prefeitura, 486,5 $\mathrm{km}^{2}$ em área territorial e 19.633 habitantes a partir do censo do IBGE de $2019 .{ }^{1}$

O município é composto por uma zona urbana e uma zona rural, sendo a última a maior parte do território, embora com menor densidade populacional. Estima-se, porém, que a maior parte da população resida na zona rural. Nesta área, grande parte da população vive da agricultura, especialmente do cultivo de café, uma atividade sazonal. Portanto, a economia do município se estabelece principalmente a partir do trabalho de plantio e colheita de café, sendo a fonte de renda para muitas famílias dos/as estudantes que frequentam as escolas do município.

Diferente das cidades vizinhas, como Manhuaçu e Santana do Manhuaçu, a organização da produção agrícola é centrada no modelo de agricultura familiar, em vez de grandes propriedades de terra, o que singulariza a dinâmica entre economia e família, trazendo desafios próprios à sociedade simonesiense. ${ }^{2}$ A sazonalidade da colheita apresenta-se como causa de um desses desafios, uma vez que parte das famílias exerce trabalho informal de colheita de café em fazendas de terceiros e depende de uma boa colheita para sua renda anual. O pagamento para recolher o grão de café é feito por quantidade, medida por "sacas", motivo pelo qual a participação de todos os membros da família torna-se essencial. A insegurança com o montante adquirido, sem garantia de direitos trabalhistas, e a antecipação de obter os ganhos necessários para a sobrevivência

\footnotetext{
1 Informações disponíveis em: https://www.simonesia.mg.gov.br; https://www.ibge.gov.br/cidades-eestados/mg/simonesia.html. Acesso em: 26 nov. 2019.

${ }^{2}$ Informações obtidas através da vivência do/da docente na região e do trabalho nas referidas escolas, além de conversas com famílias de alunos/as e pessoas nativas de Simonésia. Os/as docentes residiram dois anos na região (entre 2017 e 2019).
} 
até a colheita do ano seguinte, levam a um abandono temporário do sistema de ensino por diversos/as alunos/as, um problema contínuo enfrentado pelo município. ${ }^{3}$

A escola onde foi desenvolvida a atividade do jogo localiza-se na zona urbana, em uma região próxima ao centro da cidade, embora haja estudantes que moram tanto na área urbana quanto na zona rural. Uma porcentagem significativa dos/as estudantes provém de diferentes localidades da zona rural, seja de seus dois distritos, seja de núcleos populacionais de menor porte, como os chamados "córregos", "povoados" ou "comunidades", chegando até a escola através de transporte escolar. Em um mapeamento geral das turmas de sextos anos em que foram desenvolvidas as atividades, os/as alunos/as pertenciam a localidades diferentes, bem como possuíam condição social diferenciada. Ainda, notou-se uma variação na idade dos/as discentes, de dez a doze anos para a maioria da turma, mas também com estudantes de treze a quinze anos de idade. As turmas eram compostas por cerca de 15 a 25 estudantes, em uma sala de tamanho apropriado e carteiras individuais. A escola, de um modo geral, possui boas instalações, embora haja limitações especialmente no uso de suportes de tecnologia.

\section{Ensino de História e jogos}

Pensar o lúdico dentro da sociedade e de sua história tem sido um trajeto corrente em pesquisas de ciências humanas e sociais desde a primeira publicação do livro de Johan Huizinga, Homo Ludens, de 1938, em que o historiador buscou refletir sobre os significados dos "jogos" na cultura. Ainda mais recentes são as propostas de pensar este mesmo lúdico no contexto do ensino de História, inserindo-se nos debates sobre o processo de ensino-aprendizagem, o papel do/a professor/a e a posição do/da aluno/a como construtor do conhecimento histórico dentro da sala de aula.

Entre livros de coletâneas de experiências docentes, monografias e artigos difundidos por diversos periódicos - de diversas áreas do conhecimento - têm se chamado a atenção para a relevância da aplicação dos jogos em sala de aula, as interações que provocam e a autonomia que propicia aos agentes do processo de produção do conhecimento histórico. ${ }^{4}$

As reflexões acerca da educação, envolvendo o ensino escolar como um todo, e o ensino de História em específico, geraram transformações nas concepções daquilo que tradicionalmente seria um processo de ensino-aprendizagem satisfatório. A alteração de conceitos e prioridades levou à análise do papel do/a professor/a e dos/as alunos/as em sala de aula e na escola, revendo paradigmas comuns no ensino. Duas reflexões depreendem-se daqui: a função da didática da História, em sua relação com a consciência histórica, e a mudança na montagem da aula.

Sobre a primeira reflexão, pode-se buscar a função da didática da História, vista enquanto disciplina autônoma e não mais como uma extensão da pesquisa histórica, como ressaltam Jorn Rüsen (2006) e Klaus Bergmann (1990). Para os autores, esta disciplina busca a reflexão sobre o "caráter efetivo, possível e necessário de processos de ensino e aprendizagem e de processos formativos da História" (BERGMANN, 1990, p. 29). Além disso, Rüsen afirma que a didática da História configura-se enquanto campo que analisa também as "[...] formas e funções do raciocínio e conhecimento

\footnotetext{
${ }^{3}$ Sobre a relação entre infância, trabalho e escola, ver os trabalhos de Tania Dauster (1992) e Maria Isabel Leite (1996).

${ }^{4}$ Entre as recentes produções, podem-se citar a coletânea de Giacomini e Pereira (2018), a publicação de artigos como de Juchem e Pereira (2018) e Carissimi e Radünz (2017), a monografia de Hüther (2016), além de produções em outras áreas, como de Rapkiewicz et al. (2006).
} 
histórico na vida cotidiana, prática. Isso inclui o papel da história na opinião pública e as representações nos meios de comunicação de massa [...]" (RÜSEN, 2006, p. 12).

Essas problemáticas ecoam na produção e no desenvolvimento do jogo, já que há uma relação específica estabelecida no jogar, que envolve identificação, reconhecimento, estranhamento e aprendizagem entre conteúdos da aula e ferramentas individuais e coletivas. Nesse sentido, é importante compreender o conceito de consciência histórica, dentro de uma de suas abordagens possíveis, como explicado pelo historiador Luis Fernando Cerri (2001), para o qual esta é uma consciência inerente ao ser humano, mediada por diversos fatores internos e externos, que se transforma conjuntamente à vida prática (CERRI, 2001, p. 100).

Além disso, a consciência histórica "dá estrutura ao conhecimento histórico como um meio de entender o tempo presente e antecipar o futuro. Ela é uma combinação complexa que contém a apreensão do passado regulada pela necessidade de entender o presente e de presumir o futuro" (RÜSEN, 2006, p. 14). Em outras palavras, os conhecimentos históricos formados se tornam fundamentais para a orientação do indivíduo no tempo, a partir da compreensão do passado e do presente em seu aspecto relacional e, com isso, o uso de ferramentas para moldar seu futuro.

Esse entendimento de consciência histórica - defendido tanto por Jorn Rüsen, em Razão histórica (2001) e em Didática da História: passado, presente e perspectivas a partir do caso alemão (2006), quanto por Agnes Heller, no livro Uma teoria da história (1993) - potencializa na prática as ponderações da didática da História, a própria disciplina de História e a atuação do/a professor/a em sala de aula.

Quanto à reflexão pertinente ao exercício do/a docente em sala de aula e seu respectivo modelo pedagógico, a historiadora portuguesa Isabel Barca indica que houve uma mudança nos paradigmas tradicionais desde a década de 1980. Como explica a autora em seu artigo "Aula Oficina: do projecto à avaliação" (2004), os modelos que denominam de "aula-conferência" e "aula-colóquio" centram-se na figura do/a professor/a: na primeira, enquanto conferencista e ator, tornando os/as alunos/as sujeitos passivos na construção do conhecimento; e na segunda, ainda que busque um caráter de agência do discente, tem no professor/a o papel principal (BARCA, 2004, p. 131-133). A concepção de que os/as discentes devem construir o conhecimento em sala de aula direciona Barca para o paradigma de "aula-oficina", na qual o/a professor/a tomaria o papel de investigador social, buscando os conceitos prévios dos/as alunos/as envolvidos/as, e indicaria atividades problematizadoras em diversas formas, para que o conhecimento pudesse ser construído a partir daí.

Entre as possibilidades de buscar a centralidade do discente no processo de ensinoaprendizagem e de propor novos formatos para repensar o espaço da sala de aula, inserem-se as atividades lúdicas, neste caso, o jogo de tabuleiro. A perspectiva dos historiadores Nilton Mullet Pereira e Marcello Paniz Giacomoni, organizadores do livro Jogos e ensino de história (2018), aborda a busca por uma "arte na aula de História". Ou seja, os autores argumentam que:

A arte na aula de História seria uma espécie de arte do encontro, que se apresenta como uma cisão onde não há o um (do aluno...) e o outro (do professor...), mas uma porção de indefinição onde o encontro pode se dar, sem a necessidade do horário, da disciplina, dos ditados ou dos exercícios; [...] (PEREIRA; GIACOMONI, 2018, p. 9).

Esta observação dos autores revela duas questões relevantes para se pensar sobre o jogo na sala de aula: a primeira com relação à necessidade de se buscar novas formas de 
pensar o espaço da escola e da sala de aula; e a segunda volta-se às concepções teóricas sobre o jogo e o lúdico, espaços de diversão e sociabilidade.

O lúdico ou "jogo", como interpretado pelo historiador e linguista Johan Huizinga (1980), no já citado livro Homo Ludens, manifesta sua importância através de uma observação direta da sociedade. Pode-se observar a reunião de fiéis torcedores ao redor de jogos e campeonatos das mais variadas modalidades, a concentração intensa de jogadores profissionais, os impactos econômicos de larga escala em marcas e empresas, ou em movimentações locais, entre assíduos apostadores, sejam de dados ou cartas.

Assim como se apresenta na organização social contemporânea, o lúdico também esteve presente na história das sociedades humanas. Em virtude desses aspectos, foi possível a Huizinga afirmar, na primeira frase de sua obra, que o jogo precederia até mesmo a cultura. ${ }^{5}$ A argumentação do historiador holandês desenvolve-se dentro da noção de que a cultura é uma concepção humana e, diferente desta, o jogo é uma prática que pode se ver presente no mundo animal (1980, p. 1).

Para o autor, o jogo seria uma essência da vida humana, ultrapassando o racional (HUIZINGA, 1980, p. 3). Para além da provocativa sugestão, torna-se evidente compreender a importância dada ao jogo por Huizinga, como um aspecto de destaque na convivência e socialização humana, no qual podemos inserir o presente debate: de seu uso no ensino de História.

Um dos aspectos mais característicos da prática lúdica está em sua elaboração de um espaço novo dentro daquele já estabelecido enquanto "real". Este seria o caso de cerimônias, rituais, jogos, festas, entre outros. Ainda com Huizinga, o jogo orienta para uma separação espacial e temporal da vida cotidiana, elaborando um mundo ao mesmo tempo diverso e pertencente ao da vida cotidiana. Em suas próprias palavras, " [...] o jogo não é a vida 'ordinária' ou 'real'. Trata-se de sair da vida 'real' para uma esfera de atividade temporária com suas próprias características” (HUIZINGA, 1980, p. 8). ${ }^{6}$

Esse caráter próprio dos jogos retorna à citação anterior sobre a busca por uma "arte na aula" e a novidade do espaço que ela pode propor ao/à professor/a e discentes. Questões próprias da tradição de sala de aula, como uma autoridade do/a professor/a, a disciplina necessária para os/as alunos/as, os horários a serem cumpridos e tarefas como copiar, ler e resolver são suspensas junto com a suspensão do lúdico, mas também revistas, uma vez que o jogo não deixa de desafiar e propor indagações.

Ao pensar sobre a inserção do jogo em sala de aula, é importante considerar que este não se trata de uma forma "sutil" de levar o conhecimento aos/às alunos/as, como aborda a historiadora Sabrina Fabiola Hüther (2016) em sua monografia:

O jogo traz para o contexto da sala de aula muito mais do que um estudo oculto do conteúdo. Ele é capaz de expor as habilidades e dificuldades, bem como proporcionar uma diferente metodologia de aprendizagem, que não puderam ser diagnosticadas nas aulas que aconteceram no modelo tradicional. (HÜTHER, 2016, p. 18).

A abordagem pelo jogo requer objetivos e ferramentas específicas, buscando a participação intensa dos/as discentes como construtores do conhecimento. Nas palavras dos historiadores Edson Antoni e Jocelito Zalla, no capítulo "O que o jogo ensina", do livro de Pereira e Giacomoni (2018), ao interrogar sobre qual a função do jogo,

\footnotetext{
${ }^{5}$ Reconhece-se o caráter ensaístico e inaugural da obra de Huizinga para o estudo dos jogos, motivo pelo qual se optou por não realizar a crítica quanto à relação estabelecida pelo autor entre o jogo e a cultura.

6 Tradução livre do original: "[...] play is not 'ordinary' or 'real' life. It is rather a stepping out of "real" life into a temporary sphere of activity with a disposition all of its own" (HUIZINGA, 1980, p. 8).
} 
explicam: “[...] o jogo é feito para brincar e brincando também se aprende. Ainda que seja difícil prever todos os resultados de um jogo, [...] sua prática implica ganhos cognitivos que podem se relacionar às aprendizagens escolares" (ANTONI; ZALLA, 2018, p. 114).

Adiciona-se que a imprevisibilidade dos resultados dos jogos não se apresenta enquanto um obstáculo, mas é parte da autonomia proposta para os/as alunos/as. Nas considerações de Pereira e Giacomoni (2018), o imprevisível forma conceitos e a capacidade de ler tanto realidades distantes no espaço e no tempo, quanto próximas ao contemporâneo (PEREIRA; GIACOMINI, 2018, p. 15), além de conferir aos/às alunos/as um sentimento de pertencer e decidir sobre os rumos da história (p. 16).

Tendo essas colocações por base, as interpretações sobre os caminhos desenvolvidos pelo jogo proposto em sala de aula também serão auxiliadas pelas definições do sociólogo Roger Caillois (2001) em seu livro Man, Play and Games. Dialogando com o anteriormente exposto, Caillois ressalta o caráter de diversão da prática do jogo. Em seu esforço sistemático, o sociólogo francês busca definir o jogo tomando seis principais pontos: 1. A liberdade para se jogar; 2. A separação da vida "real"; 3. A imprevisibilidade dos resultados; 4. O caráter improdutivo, no sentido de produção material; 5. O governo das regras; e 6. O faz de conta (CAILLOIS, 2001, p. 9). Com exceção do quinto ponto, os demais parecem ter sido suficientemente desenvolvidos com relação ao jogo no ensino de História, ou parecem explicar-se por si.

Ao tratar do quinto ponto, pode-se elucidar que todo jogo possui regras mais ou menos delimitadas, mas isso não restringe a autonomia do jogador ou, no caso, dos/as alunos/as. Enquanto proposta de atividade, o/a professor/a traz para a sala o essencial para a realização material do jogo e determina um conjunto de normas sobre como este funcionará de maneira fluida.

A regra trata de um elemento fundamental para a criação da "esfera de atividade temporária" mencionada. Caillois opõe dois princípios, operando em extremos opostos, que nivelam a questão entre autonomia e regras: são a paidia e o ludus. O primeiro princípio se trata do "desvio, turbulência, livre improviso e alegria despreocupada" (CAILLOIS, 2001, p. 13), e o segundo é a disciplina estrita do jogo (p. 13). Há uma moderação desses extremos em cada modalidade e nível de profissionalização dos jogos. O jogo de tabuleiro indicado nesta investigação, por suas próprias características e seu vínculo ao ensino de História, possui abertura para a aparição de ambos os princípios, assim como apresenta atividades diversas dentro de uma mesma proposta de jogo, como se verá, podendo ser inserido como jogo competitivo (agôn), de sorte (alea) e de imitação (mimicry), abraçando três outras categorias propostas por Caillois em sua obra.

\section{A Grécia Antiga através do jogo e do jogar}

O jogo proposto para as aulas de História da Grécia Antiga consistiu em um mapa, cuja localização apresenta partes da Península Balcânica, como as regiões da Macedônia, Grécia Central, Tessália, Ática, Peloponeso, Creta e parte da Anatólia, ou Ásia Menor. Esse mapa foi concebido como um tabuleiro e foi dividido por casas, sendo o objetivo dos/das jogadores/as percorrer o caminho até o fim, através do lançamento de dados, determinando os movimentos de uma a três casas para frente.

O destino final seria chegar ao Monte Olimpo, após transcorrer localidades como Creta, Rodes, Troia, Atenas, entre outros. O formato do jogo continha mais de trinta casas, porém somente algumas delas estavam assinaladas com atividades a serem 
desenvolvidas e/ou respondidas, sendo que nestas casas havia uma numeração para indicar o que deveria ser feito. Assim, junto com o tabuleiro, os/as estudantes, reunidos em grupos de, no mínimo, três pessoas, receberam uma folha de instruções com o enredo do jogo, além das indicações do que deveria ser feito nas casas indicadas pelas numerações de 1 a 13 .

Nessa etapa, cada grupo criou a sua própria organização, alguns selecionaram uma pessoa que leu e organizou o jogo para a equipe (sem participar como jogador nas casas), em outros grupos um integrante realizava a leitura e participava concomitantemente, ou ainda, havia grupos em que todos realizavam a leitura parcial no decorrer do próprio jogo. Neste ponto, retorna-se ao exercício da autonomia por parte dos grupos e estudantes envolvidos no jogo, necessário para o desenvolvimento do lúdico. O diálogo e as possíveis discordâncias ocorridas no processo de elaboração do espaço do jogo de cada equipe tiveram pouca ou nenhuma interferência do/da professor/a regente, respeitando a decisão final e o acordo construído entre os/as integrantes. O ambiente de autogestão permite a elaboração de conceitos próprios dos/as alunos/as dentro de seus grupos e, mesmo a imprevisibilidade ocasionada pelas diferentes situações, potencializa o aprendizado e ganhos cognitivos para a interpretação do passado tratado (PEREIRA; GIACOMINI, 2018, p. 15).

O tabuleiro, confeccionado pelos/as docentes, foi feito a partir da ampliação e impressão do mapa, visando obter tamanho adequado para o jogo. ${ }^{7}$ Além disso, o desenho das casas foi feito à mão, adicionando-se os números e as regiões a serem destacadas, como visualizado na imagem (Fig. 1) a seguir:

Figura 1 - O jogo de tabuleiro

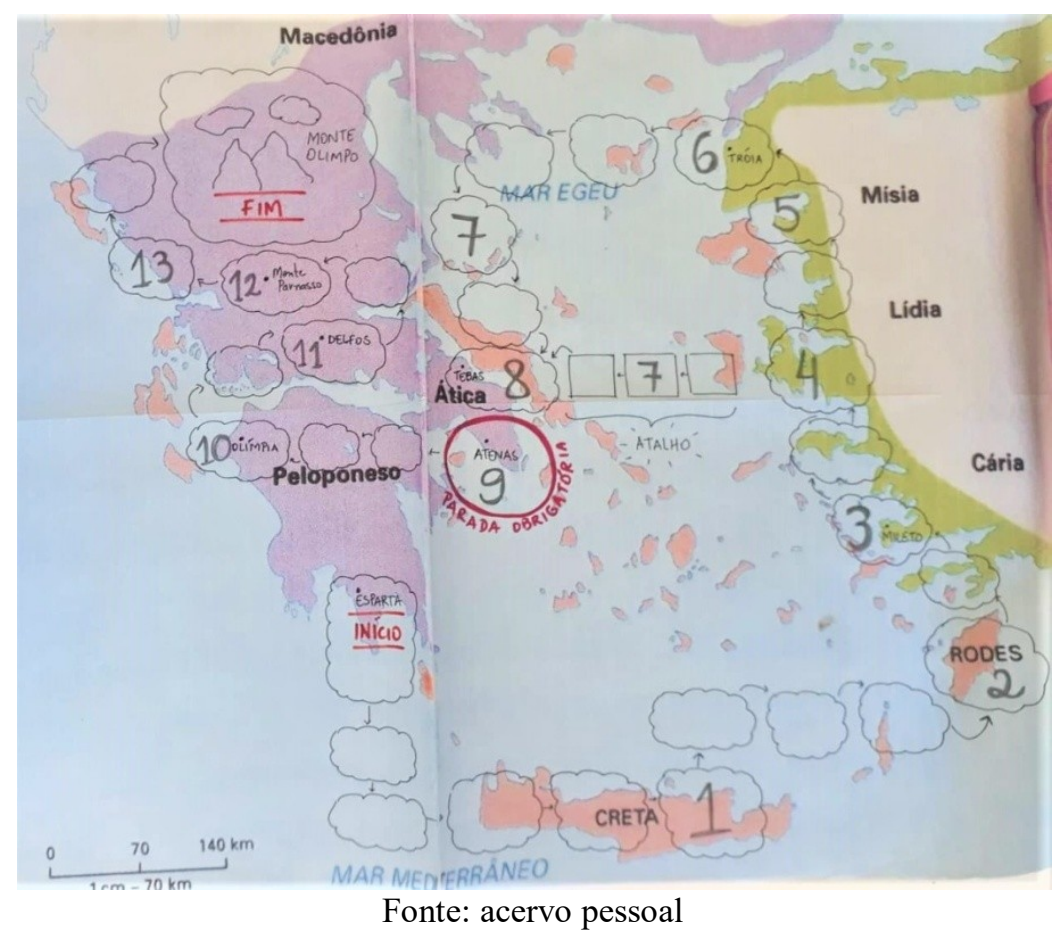

$\mathrm{Na}$ folha de instruções que os/as estudantes receberam, a aventura pela Grécia Antiga iniciava por Esparta:

\footnotetext{
${ }^{7}$ A imagem do mapa está disponível em: https://casadelasvestales.blogspot.com/2018/. Acesso em: 30 nov. 2019.
} 
Agora você é um espartano ou uma espartana que vive na Grécia Antiga, e sua cidade-Estado te deu uma missão para cumprir! Você deve dar a volta pelo Mar Egeu, passando pelos principais lugares da Grécia, para fazer uma aliança contra os persas e chegar ao Monte Olimpo, o lugar onde moram os deuses gregos, para conseguir o apoio deles também. No caminho, existem muitos obstáculos que você terá que passar.

Veja no tabuleiro o número em cada casa e olhe nesta folha o que você deve fazer em cada caso. Se você cair em uma casa sem número, siga em frente. Qualquer dúvida, pergunta para o/a professor/a! ${ }^{8}$

Destaca-se que, para o desenvolvimento de uma ambientação para o jogo, há a necessidade, por parte do/a docente, de criar uma narrativa atraente para os/as estudantes, como parte da linguagem e informação didática e como artifício de entretenimento para se jogar o jogo, acentuando a imaginação e, consequentemente, proporcionando o destaque espaço-temporal, este último como parte da própria constituição do caráter lúdico, como discutido anteriormente (HUIZINGA, 1980; CAILLOIS, 2001).

Esses recursos podem ser visualizados nesse texto inicial do jogo, em que cada jogador/a torna-se um personagem da Grécia Antiga, conjuntamente com a explicação sobre quem seriam os espartanos neste cenário da Antiguidade. Assim, nesta parte e nas outras que serão citadas ao longo do texto, a narrativa para envolvimento na história requereu o uso de recursos linguísticos, como a adjetivação, que ativam significações e compreensões sobre o desenvolvimento do jogo. Neste aspecto, evidencia-se que a forma narrativa adotada toma relevo na própria compreensão da explicação histórica, o que, por sua vez, implica duas questões relacionais: a configuração narrativa construída por parte do/a docente, o que envolve o aspecto didático e pedagógico da construção do conhecimento; bem como a forma de comunicação utilizada - o jogo - e como este impacta o próprio entendimento de um passado a ser reelaborado pelos/as estudantes.

Ademais, deve-se considerar a importância da categoria da narrativa enquanto formadora da própria história humana, já que, como fundamenta o filósofo Paul Ricoeur, em sua obra Tempo e Narrativa (1994), "[...] o tempo torna-se tempo humano na medida em que é articulado de um modo narrativo, e [...] a narrativa atinge seu pleno significado quando se torna uma condição da existência temporal" (1994, p. 85). A centralidade da narrativa, portanto, reporta à problemática tanto da historiografia quanto da didática da História, uma vez que dimensiona a relação do ser humano com o tempo, além de, potencialmente, visibilizar a existência de discursos e padrões de pensamento, estes últimos debatidos por Rüsen (2006).

A partir da contextualização inicial, a trajetória dos/das jogadores/as perpassou por diversas matérias relacionadas aos conteúdos que seriam desenvolvidos no sexto ano sobre Grécia Antiga, como a organização das cidades-Estado, a participação do cidadão na pólis, a mitologia e visão de mundo grega, as Guerras Médicas, a existência dos persas como problemática à existência do "outro", o estrangeiro, entre outros.

O levantamento dessas temáticas buscou articular conceitos relevantes tanto para o conteúdo formal de História quanto para sua compreensão no cotidiano dos/as discentes, como é o caso da participação na democracia ateniense e o exercício da cidadania, como sucederia na casa 9:

\footnotetext{
${ }^{8}$ Retirado da folha de instruções do jogo, elaborada pelos autores em 2018. Menções posteriores seguirão a mesma referência.
} 
Casa 9 - PARADA OBRIGATÓRIA! Você chegou em Atenas, uma das mais importantes cidades-Estado da Grécia Antiga, aqui todos os jogadores precisam parar. Você entrou em uma assembleia democrática e formaram a Liga de Delos, transformando Atenas e Esparta em aliadas! ${ }^{9}$ Jogue normalmente na sua próxima rodada.

A ocorrência no jogo permite que se estabeleça o diálogo sobre o que significa uma assembleia, a democracia e a cidadania, compreendendo a historicidade desses termos e suas problematizações, como a limitação para homens adultos e livres no processo de participação direta na democracia de Atenas (FUNARI, 2002). A abordagem dessas temáticas está intimamente relacionada a assuntos que pautam a sociedade e, portanto, em relação direta com a noção de consciência histórica conceituada por Rüsen (2006). A partir disso, compreende-se o desafio da formação dos/as discentes enquanto cidadãos situados em uma conjuntura e contexto histórico, marcando assim uma relação com uma história pública e com a formação de identidades.

Ao percorrer o tabuleiro, as casas construíam e reforçavam conhecimentos das aulas de História, associando um reconhecimento geográfico a partir do mapa político da Grécia. Em cada casa, os obstáculos se configuravam de formas diferentes, cada um relacionado a regiões que os/as estudantes estavam percorrendo ou a algum personagem (pertencente à mitologia ou não) referente à Antiguidade grega. Por exemplo, nas casas 1, 6 e 10, as paradas envolviam conhecer mais sobre a região de Creta, Troia e Olímpia, respectivamente, tanto as práticas culturais destes locais, envolvendo também os mitos, quanto os acontecimentos específicos, como a Guerra de Troia:

Casa 1 - Você chegou em Creta e entrou em um labirinto, é o labirinto do Minotauro, uma criatura com corpo de homem e cabeça de touro. Infelizmente a criatura te achou e você não tem mais escapatória! Volte para o início do jogo!

Casa 6 - Passando por Troia, você viu uma guerra acontecendo entre gregos e troianos, agora você deve participar de um dos lados. Tire cara ou coroa para saber se você está do lado dos gregos ou troianos. Se der CARA, você está com os gregos e ganhou a guerra, siga uma casa para frente. Se der COROA, você lutou pelos troianos e perdeu a guerra, volte duas casas.

Casa 10 - Você chegou em Olímpia, foi aqui que surgiu a ideia das olimpíadas! As olimpíadas são vários jogos disputados entre homens e mulheres em homenagem ao deus Zeus e à deusa Hera. Agora você deve escolher: faça dez polichinelos para poder jogar na sua próxima rodada ou espere duas rodadas para jogar de novo.

Ressalta-se que nem todas as informações contidas no jogo haviam sido trabalhadas previamente em sala de aula, sendo que parte do objetivo desta atividade se respaldou justamente na construção de conhecimento a partir de outra metodologia, sem necessariamente ser abordada como um reforço ao que já se havia aprendido. Neste ponto, retorna-se às considerações de Sabrina Fabiola Hüther sobre o regime de aprendizado que o jogo impõe, distinto de uma simples tradução do conteúdo em formato diverso (HÜTHER, 2016).

A partir do que os/as estudantes aprenderam através do jogo, foi possível dar prosseguimento aos conteúdos relacionados à Grécia Antiga. Por outro lado, algumas

\footnotetext{
${ }^{9} \mathrm{Na}$ busca de uma coerência narrativa, os/as docentes situaram o/a jogador/a no contexto das Guerras Médicas, inserindo-o/a como agente da elaboração da aliança entre Esparta e Atenas.
} 
questões já haviam sido abordadas em sala, como por exemplo as Olimpíadas, e a partir do jogo, foi possível retomar este tema já trabalhado e aprofundá-lo por meio de reconhecimento territorial e da cultura grega.

Nesse sentido, ambas as trajetórias trazem potenciais de aprendizado, tendo o jogo como um veículo relevante. Relacionado a isso, o jogo valoriza uma estruturação diferente dos conteúdos articulados e estabelece assim outras formas de vínculo dos/as alunos/as com a matéria, auxiliando na construção do conhecimento histórico, bem como articulando temáticas presentes no cotidiano dos/as discentes e, com isso, fomentando o exercício de articulação entre o passado e o presente.

Para além de características de competitividade e sorte no jogo apresentado, ambas as categorias abordadas por Roger Caillois (2001), também foram propostas abordagens ligadas à performance e à representação, como na casa 10 , anteriormente citada, e na casa 2:

Casa 2 - Você está passando por Rodes. Neste lugar, existe uma das mais altas estátuas do mundo antigo, chamada Colosso de Rodes. Se você conseguir imitar a pose desta estátua na frente da turma, você pode andar duas casas. Se não, espere sua próxima vez.

Veja a pose na imagem: [...]

A pose, neste caso, foi sugerida por uma imagem representativa do chamado Colosso de Rodes, ainda que a própria existência da estátua e sua posição possam ser contestadas na historiografia. ${ }^{10}$ A performance ligada a essas situações está sempre condicionada à disposição do/a discente para realizá-la. Considera-se que a atuação através do corpo e de gestos estabelecidos fortaleça o ambiente lúdico, assim como os laços entre o grupo. A dedicação consciente do/a aluno/a ao realizar determinada gestualidade, que diverge de atitudes consideradas normais e aceitas no cotidiano escolar e de sala de aula, demonstra um investimento individual do discente na atividade proposta e o sucesso de estabelecer o ambiente lúdico mencionado. Daí a noção de "arte na aula de História" de Pereira e Giacomini (2018) e sua potência em construir com os/as alunos/as os conhecimentos históricos propostos.

Em outras casas, as equipes deveriam consultar os/as professores/as para desenvolver as atividades, como por exemplo, nas casas 3 e 8 :

Casa 3 - Chegamos em Mileto, aqui nasceu um dos grandes matemáticos da nossa história, chamado Tales de Mileto. Agora você deve responder a uma questão de matemática, pergunte para o/a professor/a! Se você acertar, ande uma casa. Se errar, tem que fazer outra questão na sua próxima rodada.

Casa 8 - Você chegou em Tebas. Neste lugar, vive uma criatura perigosíssima, com corpo de leão e cabeça de ser humano, é a Esfinge. Esta criatura não é apenas poderosa, mas também muito inteligente, e ela te dará uma charada para resolver. Pergunte para o/a professor/a e tente responder! Se você acertar, ande uma casa; se errar, fique onde está e tente uma nova charada na sua próxima rodada.

Nestas casas, o objetivo era se familiarizar com o antigo matemático Tales de Mileto, além da visualização geográfica de Mileto na Grécia, bem como conhecer a figura da Esfinge, importante dentro da mitologia e da tragédia grega. Os/as estudantes,

${ }^{10}$ Ver, por exemplo: Ricardo Martínez Lacy (2018). 
ao pararem nessas casas, deveriam chamar o/a professor/a para fornecer, respectivamente, um cálculo matemático e uma charada, selecionadas adequadamente para a turma do sexto ano; como, por exemplo, resolver contas utilizando as quatro operações matemáticas e responder às charadas de estilo "o que é, o que é".

Nesses casos, utilizou-se de ferramentas do cotidiano dos/as alunos/as e de conteúdos de outras disciplinas para desenvolver conhecimento sobre a Antiguidade grega. Também se destaca o uso da interdisciplinaridade como forma de traçar conexões entre as matérias aprendidas pelos/as alunos/as na escola, na tentativa de superar a fragmentação imposta pela organização escolar, especialmente entre ciências humanas e ciências exatas. Este exercício interdisciplinar se coloca enquanto desafio no ambiente escolar, considerando que, segundo Nilma Crusoé (2010), a abordagem interdisciplinar reflete o trabalho articulado entre docentes, bem como uma organização interativa das práticas escolares (2010).

De todo modo, embora circunscrito à disciplina de História, o jogo proporcionou uma série de diálogos possíveis, cujas potencialidades se entendem a partir da "prática interdisciplinar como uma ação dotada de sentido, portadora de valores e crenças, pautada no diálogo entre saberes que são compartilhados pelos sujeitos na e pela interação social" (CRUSOÉ, 2010, p. 44). Neste aspecto, o trabalho cooperativo fomenta uma concepção de conhecimento que compreenda as dimensões relacionais e complexas de um fenômeno e suas possíveis explicações.

\section{Considerações finais}

A concepção de um jogo de tabuleiro para tratar de temáticas da História Antiga para turmas de sexto ano do Ensino Fundamental foi motivada pelo trabalho docente no que concerne à reflexão sobre ensino de História e abordagens metodológicas diferenciadas. Assim, o texto apresentado teve por objetivo apresentar e discutir a produção deste jogo, bem como seus elementos, conjuntamente aos debates sobre os campos da didática da História e a incorporação do aspecto lúdico em sala de aula.

Considera-se que uma importante chave de leitura para o desenvolvimento de novas metodologias de ensino-aprendizagem se constitui a partir do conceito de consciência histórica, tratado ao longo do trabalho, já que carrega uma noção complexa relacional entre a História disciplina e a história vivida.

Nesse sentido, ao projetar uma atividade para discentes, é necessário refletir sobre as diversas mediações, ideias prévias e construções de conhecimento que ampliam o potencial do saber histórico produzido dentro e fora da sala de aula. Com isso, permanecem desafios quanto à mobilização de conteúdos para aproximar os/as estudantes com o passado, especialmente para que este possa ser transformado em instrumentos para o presente.

Partindo dessas questões, encontrar uma abordagem didática que potencializasse a transformação do conhecimento histórico foi o objetivo ao se propor a realização do jogo em sala de aula. Assim, o jogo, embora carregue uma autonomia inerente à ação de jogar e verse sobre causalidade e sorte, deve ser pensado como uma metodologia relevante no ensino de História. Da mesma forma, mobiliza conhecimentos interdisciplinares, a partir da noção de uma relação mais "total" entre conteúdos, como também promove uma dissolução temporária da estrutura tradicional da sala de aula, dando espaço para uma nova temporalidade, diferentes interações e organizações sociais e ação performática dos/as estudantes. 


\section{Referências}

ANTONI, Edson; ZALLA, Jocelito. O que o jogo ensina: práticas de construção e avaliação de aprendizagens em História. In: GIACOMINI, M. P.; PEREIRA, N. M. (org.). Jogos e ensino de história. Porto Alegre: Editora da UFRGS, 2018. [Recurso eletrônico].

BARCA, Isabel. Aula Oficina: do projeto à avaliação. In: BARCA, Isabel (org.). Para uma educação histórica com qualidade. Actas das IV Jornadas Internacionais de Educação Histórica. Braga: Universidade de Moinho, 2004. p. 131-144.

BERGMANN, Klaus. A história na reflexão didática. Revista Brasileira de História, São Paulo, v. 9, n. 19, 1990.

CAILLOIS, Roger. Man, Play and Games. Urbana e Chicago: University of Illinois Press, 2001.

CARISSIMI, L. B.; RADÜNZ, R. Arquivo 7.0: jogos e o ensino de História. MÉTIS: História \& Cultura, v. 16, n. 31, p. 47-69, 2017.

CERRI, Luis Fernando. Os conceitos de consciência histórica e os desafios da didática da História. Revista de História Regional, n. 6, v. 2, p. 93-112, 2001.

CRUSOÉ, Nilma M. C. Prática pedagógica interdisciplinar na escola fundamental: sentidos atribuídos pelas professoras. Tese (Doutorado em Educação) - Centro de Ciências Sociais Aplicadas, Natal: Universidade Federal do Rio Grande do Norte, 2010.

DAUSTER, Tania. Uma infância de curta duração: trabalho e escola. Cad. Pesq., São Paulo, n. 82, p. 31-36, 1992.

FERMIANO, M. A. B. O jogo como um instrumento de trabalho no ensino de História. Revista História Hoje, v. 3, n. 7, 2005.

FUNARI, Pedro Paulo. Grécia e Roma. São Paulo: Contexto, 2002.

GIACOMINI, M. P.; PEREIRA, N. M. (org.). Jogos e ensino de História. Porto Alegre: Editora da UFRGS, 2018. [Recurso eletrônico].

HELLER, Agnes. Uma teoria da história. Rio de Janeiro: Civilização Brasileira, 1993.

HUIZINGA, Johan. Homo Ludens. A study of the play-element in culture. Londres: Routledge \& Keegan Paul Ltd., 1980.

HÜTHER, S. F. Jogando com a história: diferentes possibilidades de aprendizagem. Monografia (Licenciatura em História) - Centro Universitário Univates, Lajeado, 2016.

IBGE. Cidades e Estados: Simonésia. Disponível em: https://www.ibge.gov.br/cidadese-estados/mg/simonesia.html. Acesso em: 26 nov. 2019. 
JUCHEM, H.; PEREIRA, N. M. Sobre o uso de jogos no ensino de História. Revista Brasileira de Educação Básica, v. 3, n. 7, p. 1-10, 2018.

LEE, Peter. Por que aprender história? Trad. M. A. Schmidt e M. Fonza, Educar em Revista, Curitiba, n. 42, p. 19-42, 2011.

LEITE, Maria Isabel F. P. Crianças do campo - os mudos da história? Estudos Sociedade e Agricultura, Rio de Janeiro, v. 6, p. 170-191, 1996.

MARTÍNEZ LACY, R. El Coloso de Rodas y el terremoto de 228 a. C. Nova Tellvs, 36/2, p. 145-148, 2018.

PREFEITURA MUNICIPAL DE SIMONÉSIA. História. Cidade. Disponível em: https://www.simonesia.mg.gov.br. Acesso em: 26 nov. 2019.

RAPKIEWICZ, C. E. et al. Estratégias pedagógicas no ensino de algoritmos e programação associadas ao uso de jogos educacionais. Novas Tecnologias na Educação, v. 4, n. 2, 2006.

RICOEUR, Paul. Tempo e Narrativa (Tomo I). Campinas: Papirus, 1994.

RÜSEN, Jörn. Didática da História: passado, presente e perspectivas a partir do caso alemão. Práxis Educativa, Ponta Grossa, v. 1, n. 2, p. 7-16, 2006.

. Razão histórica. Teoria da história: os fundamentos da ciência histórica. Tradução de Estevão de Rezende Martins. Brasília: Ed. UnB, 2001.

SCHMIDT, M. A.; URBAN, A. C. Aprendizagem e formação da consciência histórica: possibilidades de pesquisa em educação histórica. Educar em Revista, Curitiba, n. 60, p. 17-42, 2016.

Recebido em 01 de dezembro de 2019

Aceito em 31 de maio de 2020 